\title{
Synthesis of Silver Nanoparticles Using Dichloromethane Extract of Chrysanthemum cinerariaefolium and Its Bioactivity
}

\author{
Caroline Jepchirchir Kosgei, Egerton University, Kenya* \\ Meshack Amos Obonyo, Egerton University, Kenya \\ (iD) https://orcid.org/0000-0002-5826-7109 \\ Josphat Clement Matasyoh, Egerton University, Kenya \\ James J. Owuor, Technical University of Kenya, Kenya \\ (iD) https://orcid.org/0000-0002-5611-8249 \\ Moses A. Ollengo, Dedan Kimathi University of Technology, Kenya \\ (iD) https://orcid.org/0000-0002-8649-0578 \\ Beatrice N. Irungu, Kenya Medical Research Institute, Kenya
}

\begin{abstract}
Common methods of synthesizing metallic nanoparticles are chemical and physical. However, they are expensive and use toxic chemicals. Green synthesis is less costly and safer, hence a potential alternative. Silver nanoparticles (Ag NPs) were synthesized using dichloromethane extract of Chrysanthemum cinerariaefolium, and colour change from pale green to dark brown was observed. Scanning electron microscopy (SEM) images were faceted, and others formed clusters. Transmission electron microscopy (TEM) images were spherical with an average size of $22.8 \pm 17.5 \mathrm{~nm}$. EDX analysis showed the nanoparticles had percentage abundance of $67.26 \%$. Fourier-transform infrared spectroscopy (FTIR) analysis showed absorption bands at $3489.59 \mathrm{~cm}-1,3217.80 \mathrm{~cm}-1,2384.74 \mathrm{~cm}-1$, $1633.05 \mathrm{~cm}-1,1405.08 \mathrm{~cm}-1,1109.32 \mathrm{~cm}-1$, and $505.93 \mathrm{~cm}-1$. The UV-Vis analysis showed surface plasmon resonance (SPR) peak at $434 \mathrm{~nm}$. The nanoparticles were more active on P. aeruginosa with an MIC of $15 \mu \mathrm{g} / \mathrm{ml}$ while the cytotoxicity assay showed Ag NPs had an MIC of $33.33 \mu \mathrm{g} / \mathrm{ml}$, and hence, were noncytotoxic against Vero cells.
\end{abstract}

\section{KEYWORDS}

Bioassay, Characterization, Cytotoxicity, Nanoparticles, Synthesis

\section{INTRODUCTION}

Bacteria are the oldest form of life on earth. They are responsible for a variety of infections affecting humans, animals and plants (Reta et al., 2019). In a study done in South China, bacteria was the leading causative agent of food borne illness with $44.93 \%$ followed by poisonous plants at $33.33 \%$ (Li et al., 
2018). The emergence of resistant bacterial strains to various convectional drugs has necessitated a search for alternative antibacterial drugs. The use of silver in treatment of various infections dates back to ancient civilizations. In recent years, this material in form of nanoparticles has found its way back with diverse applications (Aritonang et al., 2019).

Nanoparticles are molecules that have a size ranging from approximately 1-100 $\mathrm{nm}$ and in one dimension. Due to their small sizes, the nanomaterials/nanoparticles possess novel physiochemical and biological properties, leading to their widespread application in various areas such as health, electronics, space industries, drug-gene delivery, energy science, optoelectronics, and catalysis (Nikam et al., 2014). They are classified as organic nanoparticles, (fullerenes), inorganic nanoparticles (magnetic and noble metal nanoparticles) and semiconductor nanoparticles (e.g. titanium oxide and zinc oxide). Inorganic metal nanoparticles (Gold and silver) have gained more attention due to superior properties and functional versatility (Devi et al., 2020).

The immense antibacterial properties of silver nanoparticles (Ag NPs) and toxicity to cells have made these molecules find great demand in comparison to other nanoparticles in the medical field (Vance et al., 2015). As a result, Ag NPs have been used in production of wound dressing agents, food packaging materials, incorporation into water purification system, coating of medical devices, antiseptics in health care delivery, personal healthcare products, and textile coatings (Tran and Le, 2013; Li et al., 2013; Thakare and Ramteke, 2017; von Goetz et al., 2013). The anticancer properties of silver nanoparticles are associated with the anti-angiogenic and anti-proliferative properties of these molecules (Rani et al., 2009).

Silver nanoparticles can be synthesized using chemical, photochemical, and physical methods. However, these methods are expensive and environmentally unfriendly (Hemlata, et al 2020). Plant-based synthesis of nanoparticles provides an alternative to the aforementioned methods due to cost-effectiveness and eco-friendliness(Gengan, et al 2013). This is because plants possess phytochemicals which act as reducing and stabilization agents in the synthesis of the nanoparticles. These phytochemicals are; flavanoids, alkaloids, terpenoids, steroids, tannins, and phenols among others (Swarnalatha et al., 2013). Plants are also widely available, provide simple, and one-step method that does not require culturing or purification (Reda et al., 2019). Some of the studies displaying use of plant extracts in the synthesis of silver nanoparticles include synthesis of Ag NPs using Ananas comosus (pineapple juice)(Ahmad and Sharma, 2012) and biogenic synthesis of Silver Nanoparticles using Phyllanthus emblica fruit extract (Masum et al., 2019).

Although silver nanoparticles have been successfully synthesized using plant extracts (FemiAdepoju et al., 2019), a search for nanoparticles with precise biological, physical, and chemical features is still at the cutting edge of nanoscience research. To the best of our knowledge, synthesis of Ag NPs using Chrysanthemum cinerariaefolium (pyrethrum) has not been done, hence in the current study, silver nanoparticles were synthesized using dichloromethane extract of $C$. cinerariaefolium. The dichloromethane extract was chosen following prior laboratory analysis, which showed that the extract contained phytochemicals such as tannins, flavonoids and phenols which have been shown to act as stabilizers and reductants in the synthesis of silver nanoparticles (Swarnalatha et al., 2013).

The nanoparticles were also characterized using Scanning Electron Microscopy/Energy Dispersive X-Ray (SEM/EDX), Transmission Electron Microscopy (TEM), Fourier-transform Infrared Spectroscopy (FTIR), and UV-visible Spectroscopy (UV-vis). Phytochemical analysis of the crude extract was also carried out. Antibacterial activity of the nanoparticles was determined against Staphylococcus aureus, Pseudomonus aeruginosa, Shigella sonnei and MRSA whereas cytotoxicity studies carried out against Vero cells. The bacteria S. aureus, P. aeruginosa and MRSA were chosen due to their association with life threatening hospital infections (Paling et al., 2020, Nathwani et al., 2014). Moreover, S. sonnie was chosen since it causes shigellosis a global endemic affecting children, with greater incidence of mortality and morbidity occurring in Africa (Rogawski McQuade et al., 2020). 


\section{MATERIALS AND METHODS}

\section{Preparation of C. Cinerariaefolium Dichloromethane Crude Extract}

Pyrethrum flowers were collected from local farmers in Elgeyo-Marakwet County, latitude 00 10' to 0052 " N, Longitude 35025 " to 35045 " E and altitude of $8389 \mathrm{~m}$ above sea level. Twenty grams of powdered flower material were extracted in $100 \mathrm{ml}$ dichloromethane at room temperature and evaporated to dryness under reduced pressure. The dichloromethane crude extract was then used for the green synthesis of silver nanoparticles.

\section{Preparation of Silver Nanoparticles}

Synthesis of silver nanoparticles was done according to (De Soyza et al., 2017). Dichloromethane extract $(0.05 \%)$ was prepared by dissolving the dichloromethane crude extract $(12.5 \mathrm{mg})$ in a minimum volume of Dimethyl sulphoxide (DMSO) $(1 \mathrm{~mL})$, into which distilled water $(24 \mathrm{~mL})$ was added. 1 $\mathrm{mM}$ silver nitrate solution $(25 \mathrm{~mL})$ was mixed with same volume of $0.05 \%$ extract and the resulted mixture incubated at $30^{\circ} \mathrm{C}$ in dark on a linear shaker. Synthesis of silver particles was monitored by using UV-visible spectrophotometer (Agilent technologies cary 60) at 0, 3, 12, 24 and 48 hrs. Observing a color change of the extracts from pale green to dark brown also indicated formation of nanoparticles and clusters of nanoparticles. Thereafter, the nanopreparation was centrifuged at 5000 rpm for 10 minutes. The supernatant was discarded and the pellet containing silver nanoparticles was air dried in the incubator.

\section{Characterization of Silver Nanoparticles}

\section{UV-Visible Spectroscopy}

The colloidal suspension containing the nanoparticles was first diluted with distilled water in a ratio of (1:10). The diluted samples were then scanned using a UV-visible spectroscopy (Agilent technologies Cary 60) between $300 \mathrm{~nm}$ and $700 \mathrm{~nm}$. The UV-vis spectra of the dichloromethane flower extract and silver nitrate solution were also recorded. Distilled water was used as a blank.

\section{Scanning Electron Microscopic Analysis}

The surface characteristics of the synthesized silver nanoparticles were determined using scanning electron microscope (SEM Carl Zeiss Ultra Plus). The sample was first converted to a dry powder then gold coated using a sputter coater and mounted on a sample handler. It was then followed by scanning the sample using a focused beam of electrons. The details pertaining applied voltage, magnification used and size of the contents of the images were implanted on the images itself. The elemental analysis of the nanoparticles was carried out by energy dispersive X-ray analysis using (EDS) analyzer (Oxford X max) attached on the scanning electron microscope.

\section{Transmission Electron Microscopic Analysis}

Transmission electron microscope (TEM JEOL, JEM 1010) operating at both normal and high resolution modes (HR TEM) was used to visualize the morphology of the Ag NPs. The silver nanoparticles were first dissolved in methanol and a sample of $5 \mu \mathrm{l}$ was placed onto the carbon coated copper grid and a thin film of the sample was made on the grid. This was followed by drying overnight in a vacuum.

\section{Fourier-Transform Infrared Spectroscopy (FTIR)}

FTIR analysis of dried Ag NPs was carried out through the potassium bromide (KBr) pellet (FTIR grade) in 1: 100 ratio. The samples were scanned using infrared in the range of $4000-400 \mathrm{~cm}^{-1}$ using Fourier Transform Infrared Spectrometer (FTIR-600 FTIR SPECTROMETER). The spectral data obtained were compared with the reference chart to identify the functional groups present in the sample. 


\section{Phytochemical Analysis of Dichloromethane Crude Extract}

Phytochemical analysis of the dichloromethane extract was done qualitatively, using standard methods adapted from (Balamurugan, et al., 2019). The tested phytochemicals were tannins, saponins, flavonoids, alkaloids, phenols, glycosides, and terpenoids.

\section{Test for Tannins}

To $5 \mathrm{ml}$ of extract, a few drops of neutral $5 \%$ ferric chloride solution was added, the production of dark green colour indicated the presence of tannins.

\section{Test for Saponins}

A few $\mathrm{ml}$ of distilled water was added to $0.5 \mathrm{mg}$ of the extract and vigorously shaken. Formation of a froth indicated presence of saponins.

\section{Test for Flavonoids}

To $1 \mathrm{ml}$ of extract, $10 \%$ of lead acetate was added. The yellow precipitate formed was a positive

\section{Inference for the Flavonoids}

\section{Test for Terpenoids (Salkowski test)}

A mixture of $3 \mathrm{ml}$ of the extract and $1 \mathrm{ml}$ of chloroform was prepared. To the mixture, $1.5 \mathrm{ml}$ of concentrated $\mathrm{H}_{2} \mathrm{SO}_{4}$ was added along the sides of the tube. The reddish brown colour at the interface was considered a positive test for the presence of terpenoids.

\section{Test for Glycosides}

Approxiamtely $2 \mathrm{ml}$ of extract was mixed with about $0.4 \mathrm{ml}$ of glacial acetic acid containing traces of ferric chloride. To the mixture, $0.5 \mathrm{ml}$ of conc. $\mathrm{H}_{2} \mathrm{SO}_{4}$ was added. The production of blue colour was positive for glycosides.

\section{Test for Alkaloids}

To $5 \mathrm{ml}$ of extract, $2 \mathrm{ml}$ of $\mathrm{HCl}$ was added. About $1 \mathrm{ml}$ of dragendroffes reagent was then added. An orange or red precipitate showed a positive result for alkaloids.

\section{Test for Phenols}

To $5 \mathrm{ml}$ of extract, $3 \mathrm{ml}$ of $10 \%$ lead acetate solution was added and mixed gently. The

Production of bulky white precipitate indicated presence of phenols.

\section{ANTIBACTERIAL ASSAY}

\section{Test Micro-Organisms}

Four bacterial strains $S$. aureus (ATCC 25923), P. aeruginosa (ATCC 27853), S. sonnei (ATCC 25931) and MRSA (Clinical isolate) were used for assay of antibacterial activities. The four were obtained from Kenya Medical Research Institute (KEMRI).

\section{Disc Diffusion Assay}

Antibacterial activity of synthesized Ag NPs were ascertained using disc diffusion method according to Clinical and Laboratory Standards Institute (2009). Suspension of selected micro-organism 1.e P. aeruginosa, S. areus MRSA, and S. sonnie were subcultured on Mueller-Hinton agar and swabbed evenly onto individual agar using sterile cotton swabs. Sterile paper discs $6 \mathrm{~mm}$ in diameter 
impreginated with $500 \mu \mathrm{g} / \mathrm{ml}$ of $\mathrm{Ag} \mathrm{NPs}, 0.05 \%$ dichloromethane extract (control), $\mathrm{Ag} \mathrm{NO}_{3}$ solution $(1 \mathrm{mM})$ (control), chloramphenicol (positive control) and 1\% DMSO (negative control) were used. The experiment was replicated 3 times. Zones of inhibition were measured in millimeter $(\mathrm{mm})$ after $24 \mathrm{hrs}$ of growth and its mean \pm SD determined. Determination of Minimum Inhibitory concentration (MIC) was also done on the extract that caused inhibition above $10 \mathrm{~mm} \pm \mathrm{SD}$.

\section{Determination of Minimum Inhibitory Concentration (MIC)}

The MIC was determined using the microdilution method as described by NCCLS, (2000). Serial two-fold dilutions of Ag NPs against $P$. aeruginosa was prepared in a 96-well microtiter plate, obtaining a concentration range from $500 \mu \mathrm{g} / \mathrm{ml}$ to $15.625 \mu \mathrm{g} / \mathrm{ml}$. It was followed by addition of $5 \mu \mathrm{l}$ of $P$. aeruginosa suspension to the wells containing the dilutions. Each dose was assayed in triplicate. Uninoculated wells containing sterile saline and Ag NPs were used as controls. After incubation for $24 \mathrm{hrs}$ at $37^{\circ} \mathrm{C}$, the samples were observed. MIC was recorded as the lowest concentration of Ag NPs that inhibited the bacterial growth minimumly as detected by reduction in turbidity.

\section{CYTOTOXICITY ASSAY}

The nanoparticles were subjected to in vitro cytotoxicity against Vero cells using MTT colorimetric assay (Mosmann, 1983). The cells were acquired from KEMRI Nairobi. The Cells were first grown in Minimum Essential Medium (MEM) Eagle's Base supplemented with 15\% Fetal Bovine Serum (FBS), $2.62 \mathrm{~g} / \mathrm{L} \mathrm{NaHCO}_{3}, 20 \mathrm{mM} \mathrm{L}$-glutamine, $10 \mathrm{ml} / \mathrm{L}$ Penstrep $0.5 \mathrm{mg}$, and Fungizoid using a T-75 culture flask for 48 hours.

After 48 hours, the Phosphate Buffered Saline (PBS) was used to wash the cells in the flask, and trypsin was used to detach the cells. An aliquot of $2.0 \times 10^{5}$ cells $/ \mathrm{ml}$ suspension was then seeded in a 96-well plate. It was then incubated at temperatures of $37^{\circ} \mathrm{C}$ for 24 hours at $5 \% \mathrm{CO}_{2}$ for the cells to attach to the plate.

Briefly, $150 \mu \mathrm{l}$ of $100 \mu \mathrm{g} / \mathrm{ml}$ of the Ag NPs, were added to row H. Serial dilutions were carried out by pipetting $50 \mu \mathrm{l}$ from wells of row $\mathrm{H}$ and adding to wells of row $\mathrm{G}$. Another $50 \mu \mathrm{l}$ was then transferred from row $\mathrm{G}$ to wells of row $\mathrm{F}$, this was carried out to row $\mathrm{B}$ and finally discarding the last $50 \mu \mathrm{l}$ of this row. This resulted in three-fold serial dilutions from row $\mathrm{H}$ to row $\mathrm{B}$. Row A acted as the cell control (cells without extract treatment). Medium control (blank medium) was also incorporated in the same plates. The plates were then incubated for 48 hours at $37^{\circ} \mathrm{C}$ and $5 \% \mathrm{CO}_{2}$.

After 48 hours, MTT was added and incubated for 2 hours at $37^{\circ} \mathrm{C}$ and $5 \%$ carbon (IV) oxide. MTT was used to determine the viable cells. The media in the 96- well plate was discarded. Fifty microliters of DMSO were kept in all the plates and shaken to dissolve the formazan crystals. The plate was then put in an ELISA reader and the absorbance read between $540 \mathrm{~nm}$ and $720 \mathrm{~nm}$. The percentage of cell viability was then calculated using the formula

$\%$ Cell Viability $=(A T-A B) /(A C-A B) \times 100($ Nemati et al., 2013)

Where $\mathrm{AT}_{=}$Absorbance value of test compound.

$\mathrm{AB}=$ Absorbance value of the blank

$\mathrm{AC}=$ Absorbance value of the control 


\section{RESULTS AND DISCUSSION}

\subsection{Colour Change and UV-vis Spectra}

When pale green dichloromethane flower extract of $C$. cinerariaefolium was mixed with colorless silver nitrate solution and kept in the dark for 48 hours, formation of Ag NPs was ascertained as signified by a color change of the mixture to dark brown color (figure 1b). The color change observed was a result of the collective oscillation of free conduction electrons in the colloidal silver nanoparticles which was then endorsed to the surface plasmon resonance (SPR) (Kharissova et al., 2013). The SPR peak was detected in a UV-visible spectrum as a localized peak at $434 \mathrm{~nm}$ (figure 2). No prominent SPR peak was observed between 410-460 $\mathrm{nm}$ regions in the UV-vis spectrum of plant extracts (figure 3) and aqueous silver nitrate. This corroborated with previous studies (Ashraf et al., 2020). The broadness of the peak in the UV-vis spectra signified increased polydispersity that was attributed to variations in the growth rates of individual particles during the nucleation step (von White et al., 2012).

Figure 1. Dichloromethane extract (a), Mixture of dichloromethane extract and Silver nitrate (Ag NPs) (b)

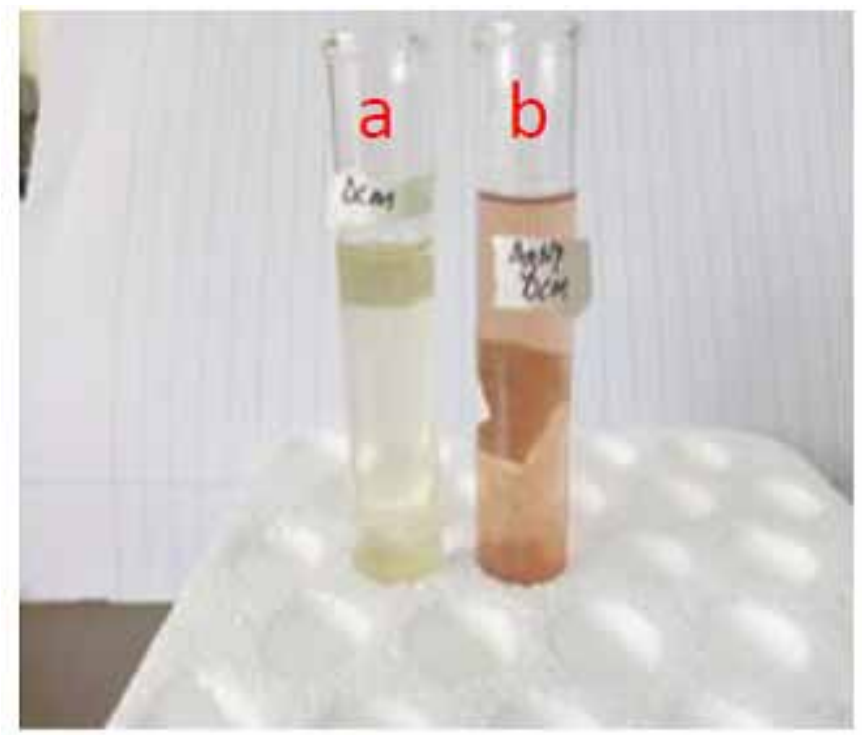

\section{Scanning Electron Microscopy (SEM), Energy Dispersive X-ray (EDX), and Transmission Electron Microscopy (TEM) Analysis}

The SEM/EDX Micrograph revealed the morphology and elemental composition of the synthesized silver nanoparticles whereas the TEM micrograph further revealed the size and shape nanoparticles. According to SEM micrograph in (figure 4), the nanoparticles were faceted and other clusters of agglomerated Ag NPs similar to what was observed Xie et al., (2016). The clusters observed in SEM could have been formed because of high concentration of the bio-reducing agents in the dichloromethane extract, leading to very small nanoparticles that tend to aggregate and resulted in the formation of larger clusters of the nanoparticles (Von White et al., 2012).

From the TEM micrographs (figure 6A), the particles were approximately spherical with a diameter of $22.8 \pm 17.5 \mathrm{~nm}$ (figure 6B). Varying sizes of spherical Ag NPs have been previously synthesized using bio-organic compounds and analyzed using TEM and SEM (Elbeshehy et al., 2015; Ghiuţă et al., 2018; Oves et al., 2018; Aziz et al., 2019). 
Figure 2. SPR Peak detection in the formed Ag NPs

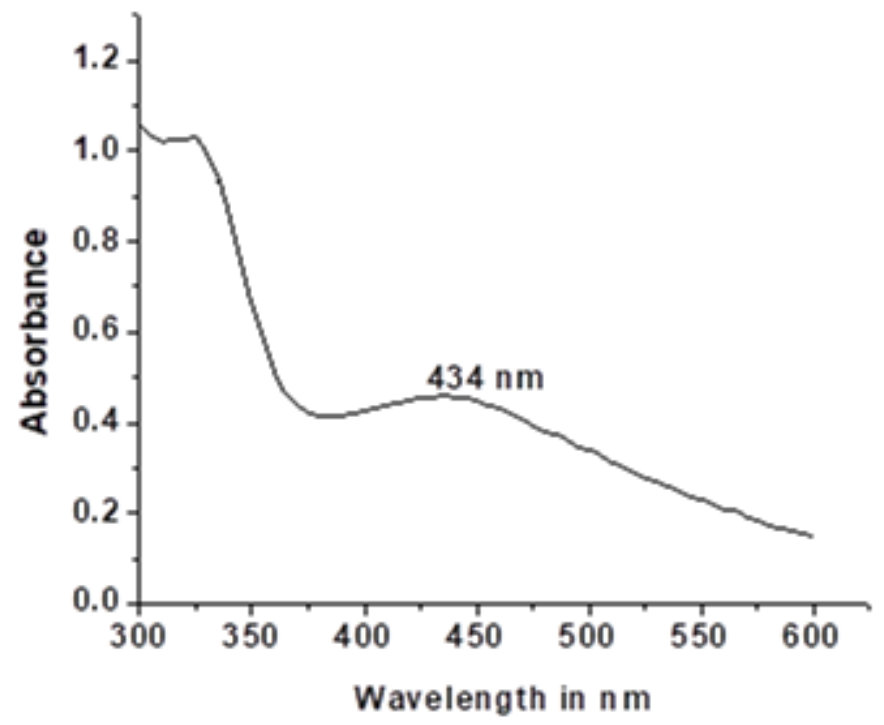

Figure 3. No SPR peak detection (dichloromethane extract)

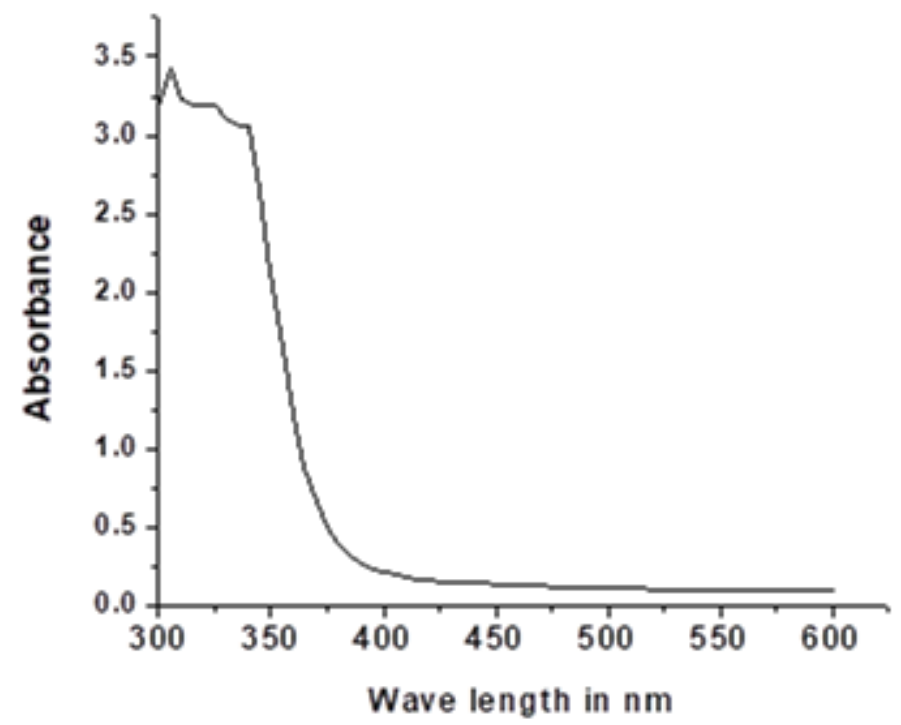


A strong signal of silver at the silver region was observed in the EDX (figure 5) an indication that the Ag NPs were successfully formed by the flower extracts of $C$. cinerariaefolium (Gopinath et al., 2015). The percentage abundance of silver was (67.26\%) while those of other elements such as Carbon and Oxygen were (26.49\%) and (6.25\%) respectively. The other EDX peaks assigned to carbon and oxygen imply that plant constituents successfully capped the nanoparticles (Dada et al., 2017d).

Figure 4. SEM image of the nanoparticles

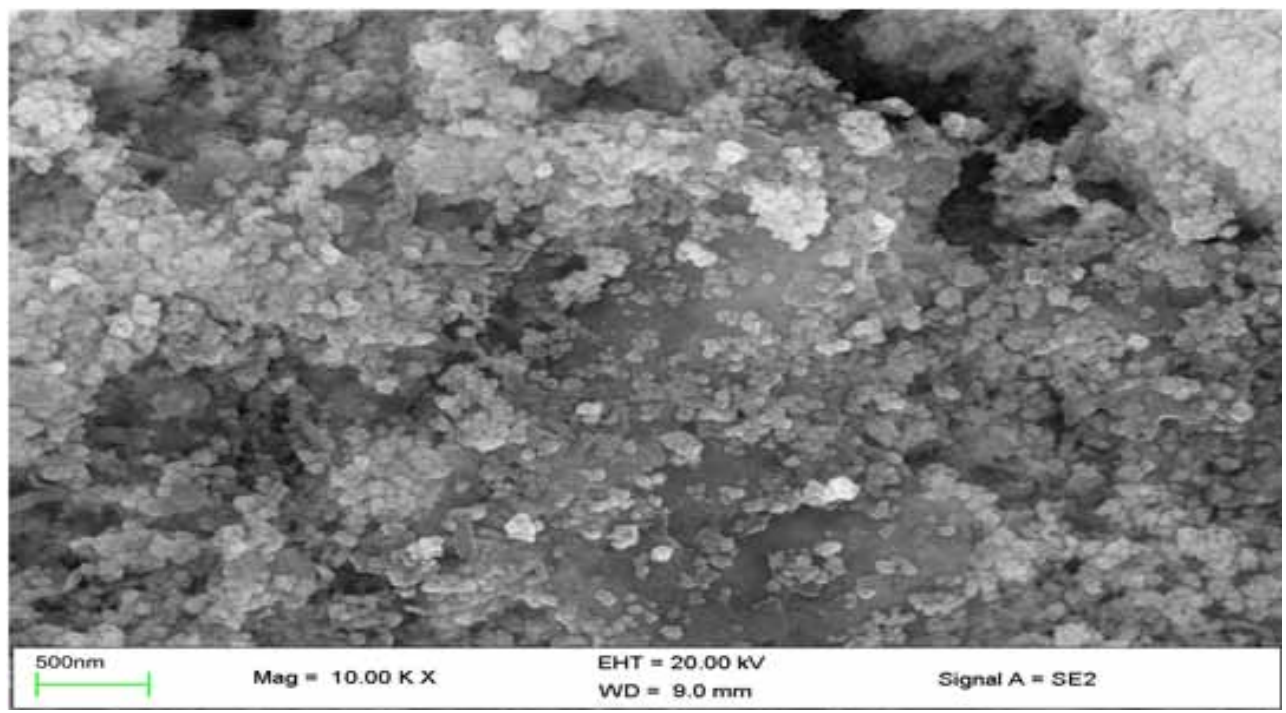

Figure 5. Observation of strong silver at silver region observed in EDX

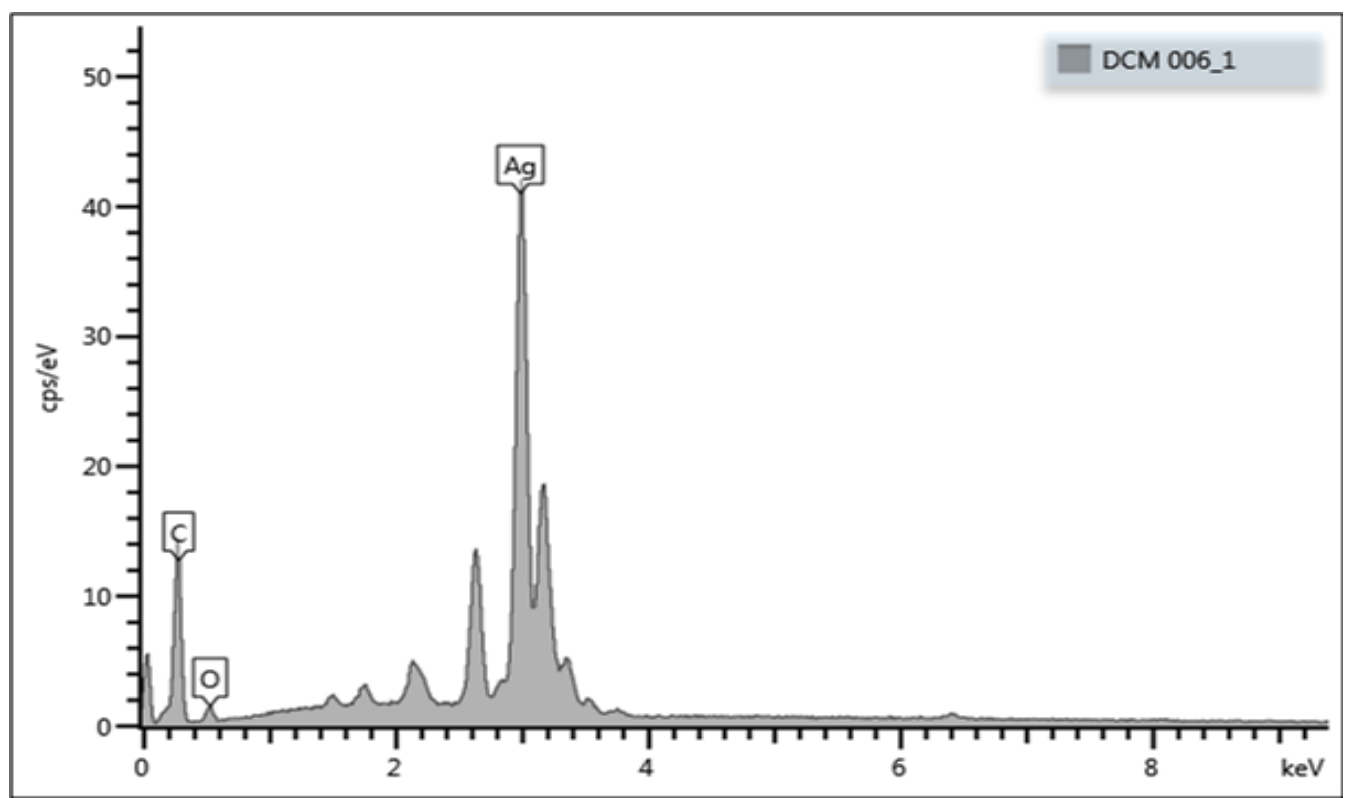




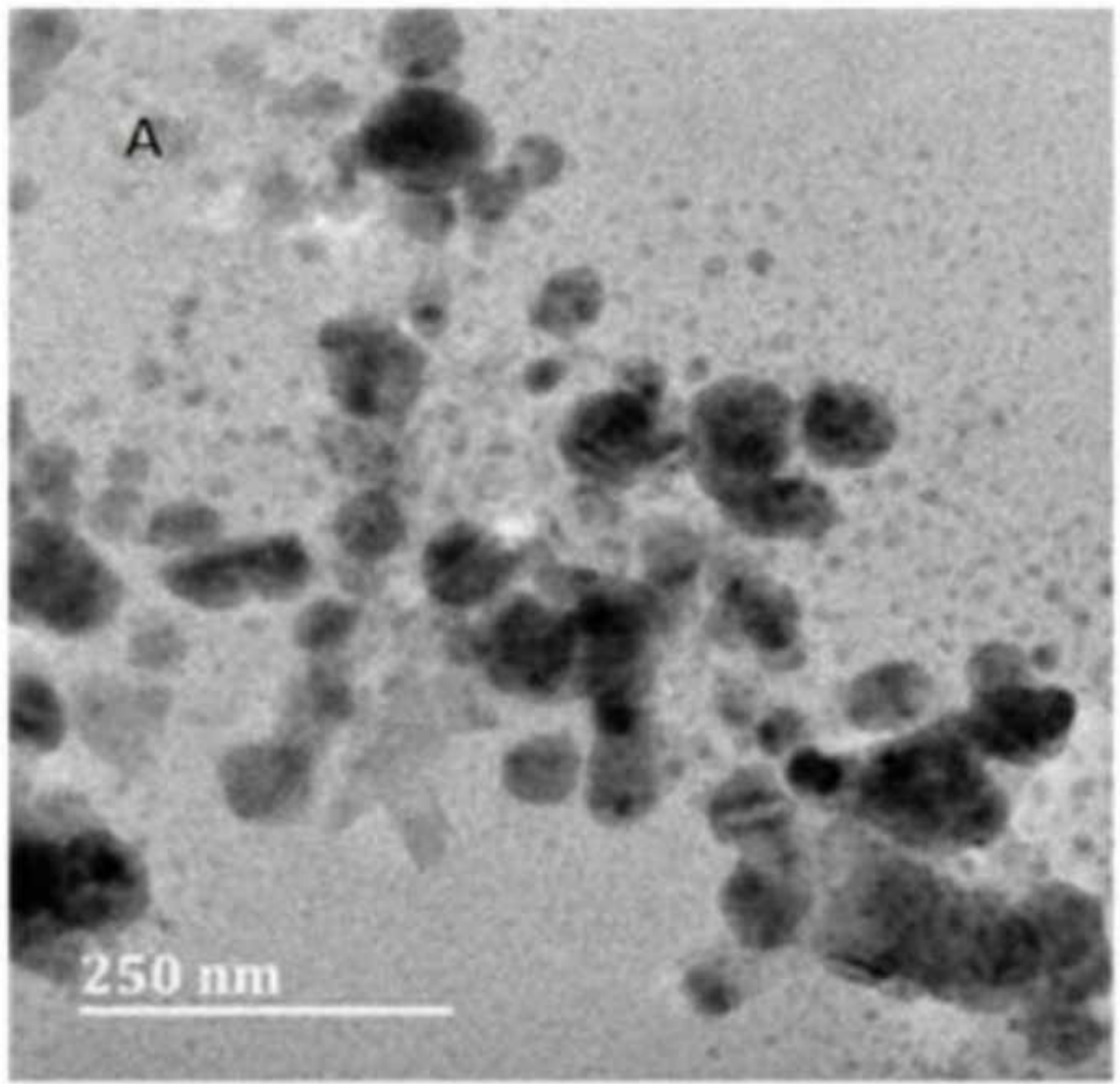

\section{FTIR Analysis}

The absorption band at $3489.59 \mathrm{~cm}^{-1}$ corresponded to the strong stretching vibrations of the hydroxyl group (-OH) belonging to phenolic compounds (Vanaja et al., 2013). Likewise, the weak stretching vibration of hydroxyl group $(\mathrm{OH})$ was observed at $3217.80 \mathrm{~cm}^{-1}$. The band at $2384.74 \mathrm{~cm}^{-1}$ was attributed to the presence of $\mathrm{C}=\mathrm{O}$ (Dorranian et al., 2012). The bands at $1633.05 \mathrm{~cm}^{-1}$, was ascribed to $\mathrm{C}=\mathrm{C}$ group present in aromatic compounds of the phytochemicals (Raghunandan et al., 2010). Moreover, C-O stretching vibration for carbonate group was observed at $1405.08 \mathrm{~cm}^{-1}$. Presence of carboxylic acid group was ascertained by the band at $1109.32 \mathrm{~cm}^{-1}$ (Pirtarighat, et al., 2019). The peaks at $505.93 \mathrm{~cm}^{-1}$ represent stretching vibrations of the metal-oxygen bond (Ag-O) (Tripathi et al., 2011). The identified functional groups in the FTIR analysis belong to phytochemicals present in the extracts. Plant phytochemicals have been reported to play a crucial role in the synthesis of nanoparticles since they act as reducing and capping agents in the reduction of metal ions to metal nanoparticles (Swarnalatha et al., 2013). As mentioned before, some of the phytochemicals that have been reported to play crucial role in the synthesis of nanoparticles are tannins, flavonoids, and phenols (Swarnalatha et al., 2013).

\section{Phytochemical Analysis}

Table 1 shows results of phytochemical analysis. Phytochemicals that were present were saponins, flavonoids, alkaloids, phenols, tannins and glycosides. The identified phytochemicals have been noted 
International Journal of Applied Nanotechnology Research

Volume $6 \cdot$ Issue 1

Figure 6(b) Particle size distribution (Ag NPs)

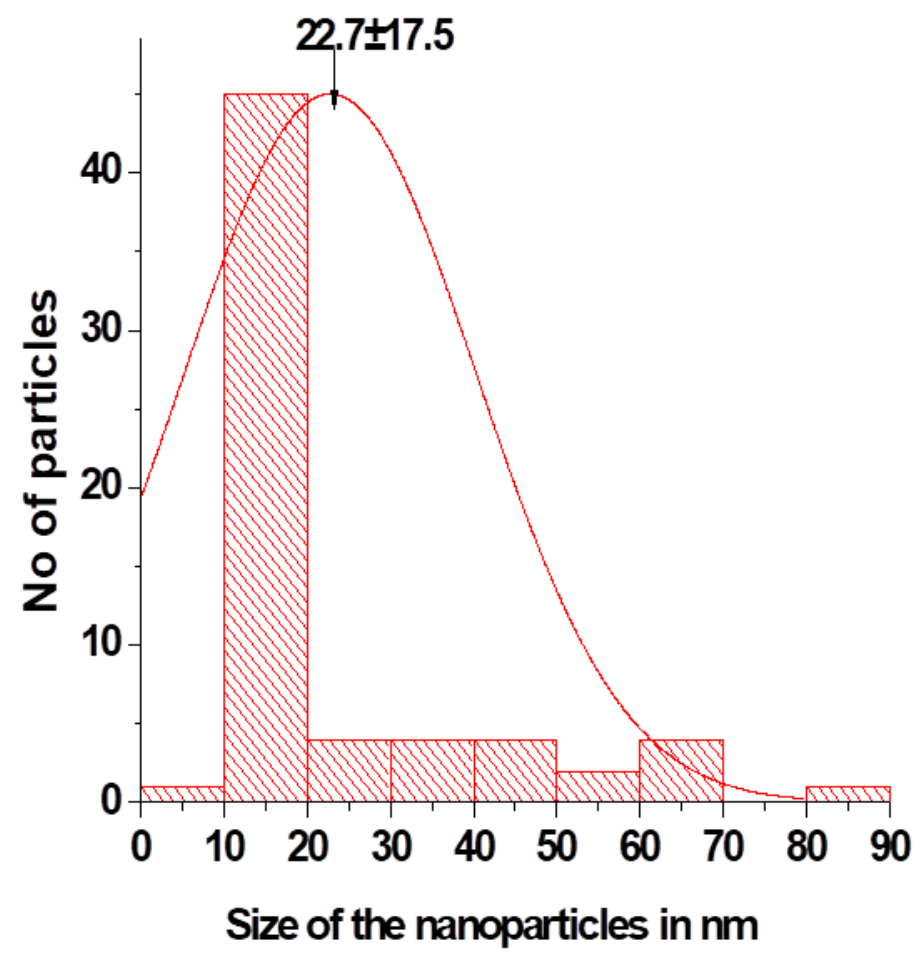

Figure 7. FTIR spectrum of the Ag NPs

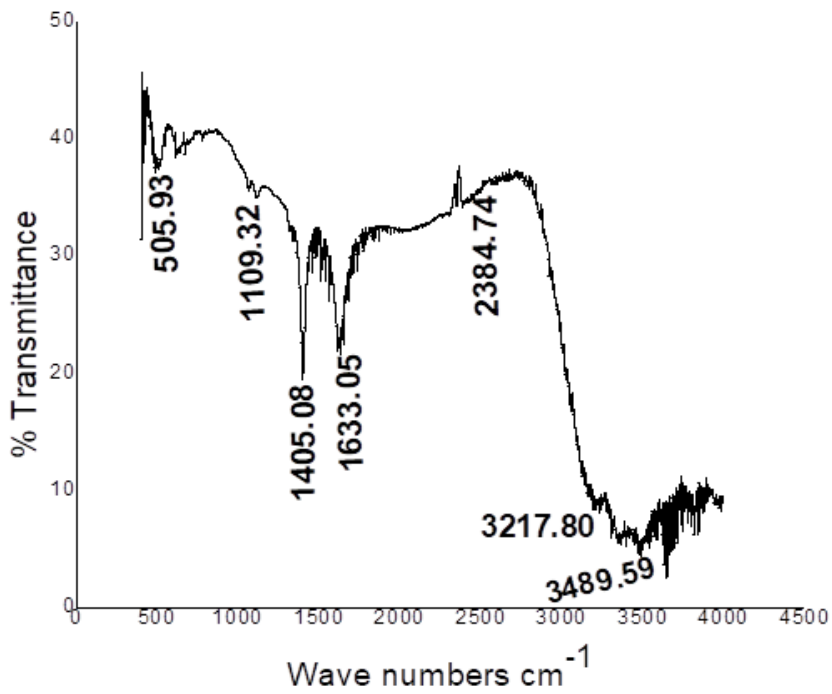


to play important role in the synthesis of metalic nanoparticles since they act as reducing and capping/ stabilizing agents in the synthesis of metal nanoparticles (Swarnalatha et al., 2013). Tulsi plant have been reported to have flavonoids, terpenoids, and phenolic compounds that were responsible for the reduction of silver ions to Ag NPs (Jain and Mehata, 2017). A study by Ajitha et al., (2015) showed that flavonoids, glycosides, and carbohydrates in Lantana camara were responsible for the synthesis of silver nanoparticles.

Flavonoids and phenolic compounds have been implicated in the synthesis of nanoparticles due to presence of hydroxyl groups and carbonyl moieties (Marslin et al., 2018).

The exact mode of action of flavonoids in reducing silver ions to nanoparticles is unknown but it might be possible that the tautomeric transformation of flavonoids from enol form to keto form could release reactive hydrogen atom that reduces silver ions to silver nanoparticles (Jain and Mehata, 2017).

Table 1. Phytochemical analysis of the dichloromethane plant extract

\begin{tabular}{|l|l|}
\hline \multicolumn{1}{|c|}{ Phytochemicals tested } & \multicolumn{1}{c|}{ Present (+) Absent (-) } \\
\hline Saponins & + \\
\hline Flavanoids & + \\
\hline Alkaloids & + \\
\hline Phenols & + \\
\hline Tannins & + \\
\hline Glycosides & + \\
\hline Terpenoids & - \\
\hline
\end{tabular}

\section{Antibacterial Activity of Dichloromethane-Ag NPs}

Results of disc diffusion assay of Chrysanthemum-dichloromethane-Ag NPs against selected bacteria are presented in Table 2. The values are the mean of three experiments \pm S.D. In the present study, the activity of Ag NPs was higher than the activity of aqueous silver nitrate and the crude plant extract against the selected bacteria which is similar to what had been observed in previous studies by Khan et al., (2016). The nanoparticles were more active against $P$. aeruginos $a$ as determined by the zone of inhibition with an MIC of $15.625 \mu \mathrm{g} / \mathrm{ml}$. The higher activity of the nanoparticles compared to aqueous silver nitrate and crude plant extracts could be attributed to their ability to attach to the cell wall and generated free radicals that disturbed the permeability of the membrane. They have also been reported to penetrate the cell membrane and cause intracellular ATP leakage leading to cell death (Franci et al., 2015). Moreover, cell membrane of bacteria have been previously noted to contain Ag NPs (Oves et al., 2018).

There was significant difference in the activity of Ag NPs on the selected bacteria although no significant difference was observed against $S$ aureus (gram positive) and $S$. sonnie (gram negative). Conflicting statements on the effect of nanoparticles on gram-positive and gram-negative bacteria have previously emerged. According to (Shrivastava et al., 2007), gram-negative bacteria are more resistant to the effect of silver nanoparticles while (Peticae et al., 2008; Kong and Jang, 2008), showed that silver nanoparticles had equal inhibitory effect against both gram-positive and gram-negative strains. The ability of Ag NPs to act on both gram-negative and gram-positive bacteria has been ascertained in other studies (Franci et al., 2015). The present study therefore further confirmed broad spectrum ability of silver nanoparticles 
Table 2. Antibacterial bioassay

\begin{tabular}{|l|l|l|l|l|}
\hline \multirow{2}{*}{ Extracts } & \multicolumn{3}{c|}{ Zone of inhibition in mm } \\
\cline { 2 - 5 } & \multicolumn{1}{|c|}{ MRSA } & \multicolumn{1}{c|}{ S. aureus } & \multicolumn{1}{c|}{ P. aeruginosa } & \multicolumn{1}{c|}{ S. sonnie } \\
\hline Ag NPs & $7.3 \pm 0.2^{\mathrm{b}}$ & $9.7 \pm 0.8^{\mathrm{c}}$ & $13.3 \pm 0.6^{\mathrm{a}}$ & $9.5 \pm 0.5^{\mathrm{c}}$ \\
\hline $\begin{array}{l}\text { (Control Dichloromethane } \\
\text { plant extract) }\end{array}$ & $6 \pm 0^{\mathrm{a}}$ & $6 \pm 0^{\mathrm{a}}$ & $6 \pm 0^{\mathrm{a}}$ & $6 \pm 0^{\mathrm{a}}$ \\
\hline Control(Silver nitrate) & $6.4 \pm 0.1^{\mathrm{a}}$ & $7.1 \pm 0.1^{\mathrm{b}}$ & $7 \pm 0.5^{\mathrm{ab}}$ & $7.1 \pm 0.4^{\mathrm{b}}$ \\
\hline DMSO+distilled $\mathrm{H}^{\mathrm{a}}$ & $6 \pm 0^{\mathrm{a}}$ & $6 \pm 0^{\mathrm{a}}$ & $6 \pm 0^{\mathrm{a}}$ & $6 \pm 0^{\mathrm{a}}$ \\
\hline Chlorampherical $^{\mathrm{P}}$ & $28.7 \pm 1^{\mathrm{c}}$ & $22.7 \pm 1.2^{\mathrm{b}}$ & $22 \pm 2^{\mathrm{b}}$ & $30.5 \pm 1.3^{\mathrm{d}}$ \\
\hline
\end{tabular}

Within a row similar letters show no significant differences while different letters show a significant difference. ${ }^{\mathrm{P}}$ Positive control, ${ }^{\mathrm{Q}}$ Negative control

\section{Cytotoxicity Assay}

From the cytotoxicity assay, Chrysanthemum-dichloromethane-Ag NPs and C. cinerariaefolium were less toxic than doxorubicin. The nanoparticles had an $\mathrm{IC}_{50}$ of $33.33 \mu \mathrm{g} / \mathrm{ml}$ (figure 7) while for doxorubicin the $\mathrm{IC}_{50}$ was $11.82 \mu \mathrm{g} / \mathrm{ml}$. According to the US National Cancer Institute (NCI), a molecule is considered cytotoxic if the $\mathrm{IC}_{50}<20 \mu \mathrm{g} / \mathrm{ml}$ (Nathyadevi and Sivakumar, 2015), hence the biosynthesized Ag NPs and the plant extracts were considered nontoxic. This agrees with a previous study that showed that Ag NPs in the range between 5 and $45 \mathrm{~nm}$ were not significantly toxic against Vero cells at all concentrations tested (Kasithevar et al., 2017).

The fact that the biosynthesized nanoparticles were near spherical could have aided in reducing the toxicity of the particles since spherical nanoparticles have been reported to be less toxic than other shapes. This is because other shapes such as the wires, hexagonal, etc. have been reported to directly contact the cell surface rather than being internalized as in spherical particles making them

Figure 8. Percentage growth of Vero cells

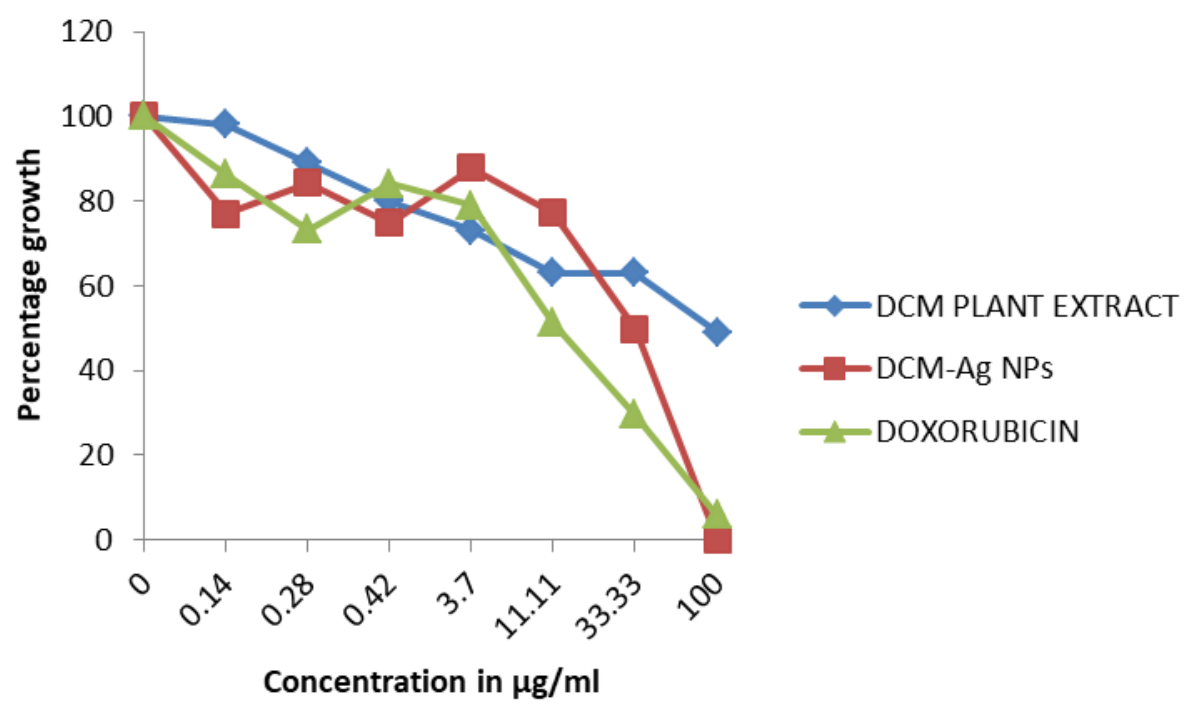


more toxic than spherical (Stoehr et al., 2011). In a study in which silver nanowires with a diameter of 100-160 nm and length of 1.5-25 $\mu \mathrm{m}$ together with spherical Ag NPs $30 \mathrm{~nm}$ in size, were subjected to human lung epithelial A549 cells, spherical particles did not show adverse effects on cytotoxic parameters in A549 cells whereas wires induced negative outcomes (Stoehr et al., 2011).

The Vero cell cytotoxicity of the nanoparticles and extracts were observed to be concentrationdependent with the highest concentrations $(100 \mu \mathrm{g} / \mathrm{ml})$ causing decreased cell growth. This has also been observed in previous studies (Prasannaraj and Venkatachalam, 2017).

\section{CONCLUSION}

Currently, a lot of attention by researchers has been focused on inorganic nanoparticles made of noble metals i.e. (gold and silver nanoparticles) due to their superior properties. They are extensively available, have good biocompatibility, good carriers of targeted drug delivery, controlled drug release, and rich functionality. In the medical field, silver nanoparticles has gained popularity because of its renown antibacterial properties hence used in wound dressing agents, coating of medical devices, antiseptics in health care delivery and personal healthcare products.

As a result of widespread applications of silver nanoparticles in the medical field and other areas, a search for better synthetic methods that are cheaper, safer, efficient and less time consuming is on the rise. Compared to other methods of synthesis such as chemical and physical which are deemed expensive and entail use of toxic chemicals, green synthesis has proved to be an alternative in the synthesis of the nanoparticles. This is because it involves use of reductants and stabilizers obtained from naturally occurring extracts such as fungi, bacteria, and plants. Plant-based synthesis has gained much acceptance because they are widely available, provide simple, and one-step method that does not require culturing or purification.

Although there are much benefits associated with synthesis of nanoparticles using plant extracts, some of the draw backs associated with this method is that same species of plants growing in different geographical areas have varying phytoconstituents, due to difference in geographical and climatic conditions. This has led to variations in time needed to synthesize the particles, and variations in size and shapes of the formed nanoparticles. This would therefore affect the efficacy of the resultant silver nanoparticles.

For large scale production of the nanoparticles there is need to identify the active ingredients in plants involved in the synthesis and produce the same ingredients in large scale. This would reduce the time needed for the synthesis and would also lead to controlled size and shape of the resultant nanoparticles, since variations in phytochemicals have been noted to affect size and shape of the formed nanoparticles. 


\section{REFERENCES}

Ahmad, N., \& Sharma, S. (2012). Green synthesis of silver nanoparticles using extracts of Ananas comosus. Green and Sustainable Chemistry, 2(4), 141-147. doi:10.4236/gsc.2012.24020

Ajitha, B., Ashok Kumar Reddy, Y., Shameer, S., Rajesh, K. M., Suneetha, Y., \& Reddy, P. S. (2015). Lantana camara leaf extract mediated silver nanoparticles: Antibacterial, green catalyst. Journal of Photochemistry and Photobiology A Chemistry, 149, 84-92. doi:10.1016/j.jphotobiol.2015.05.020 PMID:26057018

Aritonang, H. F., Koleangan, H., \& Wuntu, A. D. (2019). Synthesis of silver nanoparticles using aqueous extract of medicinal plants'(Impatiens balsamina and Lantana camara) fresh leaves and analysis of antimicrobial activity. International Journal of Microbiology, 2019, 2019. doi:10.1155/2019/8642303 PMID:31354833

Ashraf, H., Anjum, T., Riaz, S., \& Naseem, S. (2020). Microwave-assisted green synthesis and characterization of silver nanoparticles using Melia azedarach for the management of Fusarium wilt in tomato. Frontiers in Microbiology, 11, 238. doi:10.3389/fmicb.2020.00238 PMID:32210928

Aziz, N., Sherwani, A., Faraz, M., Fatma, T., \& Prasad, R. (2019). Illuminating the anticancerous efficacy of a new fungal chassis for silver nanoparticle synthesis. Frontiers in Chemistry, 7, 65. doi:10.3389/fchem.2019.00065 PMID:30800654

Balamurugan, V., Fatima, S., \& Velurajan, S. (2019). A guide to phytochemical analysis. Int. J Adv Res Inn Ideas In Ed, 5(1), 236-245.

Clinical and Laboratory Standards Institute. (2009). Methods for dilution antimicrobial susceptibility tests for bacteria that grow aerobically; approved standard (8th ed.). Clinical and Laboratory Standards Institute.

Dada, A. O., Adekola, F. A., \& Odebunmi, E. O. (2017d). A novel zero valent manganese for removal of copper ions: Synthesis, characterization and adsorption studies. Applied Water Science, 7(3), 1409-1427. doi:10.1007/ s13201-015-0360-5

De Soyza, S. G., Wijayaratne, W. M. D. G. B., Napagoda, M., \& Witharana, S. (2017). Antimicrobial Potential in Biogenic Silver nanoparticles Synthesized from Plectranthus zeylanicus. J Mol Nanot Nanom, 1(1), 105.

Devi, M., Devi, S., Sharma, V., Rana, N., Bhatia, R. K., \& Bhatt, A. K. (2020). Green synthesis of silver nanoparticles using methanolic fruit extract of Aegle marmelos and their antimicrobial potential against human bacterial pathogens. Journal of Traditional and Complementary Medicine, 10(2), 158-165. doi:10.1016/j. jtcme.2019.04.007 PMID:32257879

Dorranian, D., Solati, E., \& Dejam, L. (2012). Photoluminescence of ZnO Nanoparticles Generated by Laser Ablation in Deionized Water. Applied Physics. A, Materials Science \& Processing, 109(2), 307-314. doi:10.1007/ s00339-012-7073-5

Elbeshehy, E. K., Elazzazy, A. M., \& Aggelis, G. (2015). Silver nanoparticles synthesis mediated by new isolates of Bacillus spp., nanoparticle characterization and their activity against Bean Yellow Mosaic Virus and human pathogens. Frontiers in Microbiology, 6, 453. doi:10.3389/fmicb.2015.00453 PMID:26029190

Femi-Adepoju, A. G., Dada, A. O., Otun, K. O., Adepoju, A. O., \& Fatoba, O. P. (2019). Green synthesis of silver nanoparticles using terrestrial fern Gleichenia Pectinata (Willd.) C. Presl.): Characterization and antimicrobial studies. Heliyon, 5(4), e01543. doi:10.1016/j.heliyon.2019.e01543 PMID:31049445

Franci, G., Falanga, A., Galdiero, S., Palomba, L., Rai, M., Morelli, G., \& Galdiero, M. (2015). Review on Silver Nanoparticles as Potential Antibacterial Agents. Molecules (Basel, Switzerland), 20(5), 8856-8874. doi:10.3390/ molecules20058856 PMID:25993417

Gengan, R., Anand, K., Phulukdaree, A., \& Chuturgoon, A. (2013). A549 lung cell line activity of biosynthesized silver nanoparticles using Albizia adianthifolia leaf. Colloids and Surfaces. B, Biointerfaces, 105, 87-91. doi:10.1016/j.colsurfb.2012.12.044 PMID:23352951

Ghiuţă, I., Cristea, D., \& Munteanu, D. (2017). Synthesis methods of metallic nanoparticles: An overview. Bulletin of the Transilvania University of Brasov Series, 10, 133-140. 
Gopinath, V., Priyadarshini, S., Venkatkumar, G., Saravanan, M., \& Mubarak Ali, D. (2015). Tribulus terrestris leaf mediated biosynthesis of stable antibacterial silver nanoparticles. Pharmaceutical Nanotechnology, 3(1), 26-34. doi:10.2174/2211738503666150626160843

Hemlata, M., Meena, P. R., Singh, A. P., \& Tejavath, K. K. (2020). Biosynthesis of silver nanoparticles using cucumis prophetarum aqueous leaf extract and their antibacterial and antiproliferative activity against cancer cell lines. ACS Omega, 5(10), 5520-5528. doi:10.1021/acsomega.0c00155 PMID:32201844

Jain, S., \& Mehata, M. S. (2017). Medicinal Plant Leaf Extract and Pure Flavonoid Mediated Green Synthesis of Silver Nanoparticles and their Enhanced Antibacterial Property. Scientific Reports, 7(1), 15867. doi:10.1038/ s41598-017-15724-8 PMID:29158537

Kasithevar, M., Saravanan, M., Prakash, P., Kumar, H., Ovais, M., Barabadi, H., \& Shinwari, Z. K. (2017). Green synthesis of silver nanoparticles using Alysicarpus monilifer leaf extract and its antibacterial activity against MRSA and CoNS isolates in HIV patients. Journal of Interdisciplinary Nanomedicine, 2(2), 131-141. doi:10.1002/jin2.26

Khan, F. A., Zahoor, M., Jalal, A., \& Rahman, A. U. (2016). Green Synthesis of Silver Nanoparticles by Using Ziziphus nummularia Leaves Aqueous Extract and Their Biological Activities. Journal of Nanomaterials.

Kharissova, O. V., Dias, H. R., Kharisov, B. I., Perez, B. O., \& Perez, V. M. J. (2013). The greener synthesis of nanoparticles. Trends in Biotechnology, 31(4), 240-248. doi:10.1016/j.tibtech.2013.01.003 PMID:23434153

Kong, H., \& Jang, J. (2008). Antibacterial properties of novelpoly (methyl methacrylate) nanofiber containing silver nanoparticles. Langmuir, 24(5), 2051-2056. doi:10.1021/la703085e PMID:18225933

Li, C., Fu, R., Yu, C., Li, Z., Guan, H., Hu, D., Zhao, D., \& Lu, L. (2013). Silver nanoparticle/chitosan oligosaccharide/poly (vinyl alcohol) nanofibers as wound dressings: A preclinical study. International Journal of Nanomedicine, 8, 4131. PMID:24204142

Li, Y., Huang, Y., Yang, J., Liu, Z., Li, Y., Yao, X., Wei, B., Tang, Z., Chen, S., Liu, D., Hu, Z., Liu, J., Meng, Z., Nie, S., \& Yang, X. (2018). Bacteria and poisonous plants were the primary causative hazards of foodborne disease outbreak: A seven-year survey from Guangxi, South China. BMC Public Health, 18(1), 1-8. doi:10.1186/ s12889-018-5429-2 PMID:29669556

Marslin, G., Siram, K., Maqbool, Q., Selvakesavan, R. K., Kruszka, D., Kachlicki, P., \& Franklin, G. (2018). Secondary metabolites in the green synthesis of metallic nanoparticles. Materials (Basel), 11(6), 940. doi:10.3390/ ma11060940 PMID:29865278

Masum, M., Islam, M., Siddiqa, M., Ali, K. A., Zhang, Y., Abdallah, Y., Ibrahim, E., Qiu, W., Yan, C., \& Li, B. (2019). Biogenic synthesis of silver nanoparticles using Phyllanthus emblica fruit extract and its inhibitory action against the pathogen Acidovorax oryzae strain RS-2 of rice bacterial brown stripe. Frontiers in Microbiology, 10, 820. doi:10.3389/fmicb.2019.00820 PMID:31110495

Mosmann, T. (1983). Rapid colorimetric assay for cellular growth and survival: Application to proliferation and cytotoxicity assays. Journal of Immunology (Baltimore, Md.: 1950), 65, 55-63. PMID:6606682

Nathwani, D., Raman, G., Sulham, K., Gavaghan, M., \& Menon, V. (2014). Clinical and economic consequences of hospital-acquired resistant and multidrug-resistant Pseudomonas aeruginosa infections: A systematic review and meta-analysis. Antimicrobial Resistance and Infection Control, 3(1), 1-16. doi:10.1186/2047-2994-3-32 PMID:25371812

NCCLS. (2000). Performance standards for antimicrobial disk susceptibility tests. Approved standard (7th ed.). NCCLS. NCCLS document M2-A7.

Nemati, F., Dehpouri, A. A., Eslami, B., Mahdavi, V., \& Mirzanejad, S. (2013). Cytotoxic properties of some medicinal plant extracts from Mazandaran, Iran. Iranian Red Crescent Medical Journal, $15(11)$, e8871. doi:10.5812/ircmj.8871 PMID:24719689

Nikam, A. P., Ratnaparkhiand, M. P., \& Chaudhari, S. P. (2014). Nanoparticles an overview. International Journal of Research and Development in Pharmacy and Life Sciences, 5, 1121-1127.

Nithyadevi, J., \& Sivakumar, R. (2015). Phytochemical screening and GC-MS, FT-IR analysis of methanolic extract leaves of Solanum torvum. International Journal of Research Studies in Biosciences, 3, 61-66. 
Oves, M., Aslam, M., Rauf, M. A., Qayyum, S., Qari, H. A., Khan, M. S., Alam, M. Z., Tabrez, S., Pugazhendhi, A., \& Ismail, I. M. (2018). Antimicrobial and anticancer activities of silver nanoparticles synthesized from the root hair extract of Phoenix dactylifera. Materials Science and Engineering C, 89, 429-443. doi:10.1016/j. msec.2018.03.035 PMID:29752116

Paling, F. P., Hazard, D., Bonten, M. J., Goossens, H., Jafri, H. S., Malhotra-Kumar, S., Sifakis, F., Weber, S., \& Kluytmans, J. A. J. W.ASPIRE-ICU Study Team. (2020). Association of Staphylococcus aureus Colonization and Pneumonia in the Intensive Care Unit. JAMA Network Open, 3(9), e2012741-e2012741. doi:10.1001/ jamanetworkopen.2020.12741 PMID:32997125

Peticae, A., Gavriliu, S., Lungua, M., Burunteaa, N., \& Panzarub, C. (2008). Colloidal silver solutions with antimicroproperties. Materials Science and Engineering, 152(1-3), 22-27. doi:10.1016/j.mseb.2008.06.021

Pirtarighat, S., Ghannadnia, M., \& Baghshahi, S. (2019). Green synthesis of silver nanoparticles using the plant extract of Salvia spinosa grown in vitro and their antibacterial activity assessment. Journal of Nanostructure in Chemistry, 9(1), 19. doi:10.1007/s40097-018-0291-4

Prasannaraj, G., \& Venkatachalam, P. (2017). Hepatoprotective effect of engineered silver nanoparticles coated bioactive compounds against diethylnitrosamine induced hepatocarcinogenesis in experimental mice. Journal of Photochemistry and Photobiology. B, Biology, 167, 309-320. doi:10.1016/j.jphotobiol.2017.01.009 PMID:28129629

Raghunandan, D., Bedre, M. D., Basavaraja, S., Sawle, B., Manjunath, S., \& Venkataraman, A. (2010). Rapid biosynthesis of irregular shaped gold nanoparticles from macerated aqueous extracellular dried clove buds (Syzygium aromaticum) solution. Colloids and Surfaces. B, Biointerfaces, 79(1), 235-240. doi:10.1016/j. colsurfb.2010.04.003 PMID:20451362

Rani, P. V. A., Mun, G. L. K., Hande, M. P., \& Valiyaveettil, S. (2009). Cytotoxicity and genotoxicity of silver nanoparticles in human cells. ACS Nano, 3(2), 279-290. doi:10.1021/nn800596w PMID:19236062

Reda, M., Ashames, A., Edis, Z., Bloukh, S., Bhandare, R., \& Abu Sara, H. (2019). Green synthesis of potent antimicrobial silver nanoparticles using different plant extracts and their mixtures. Processes (Basel, Switzerland), 7(8), 510. doi:10.3390/pr7080510

Reta, A., Bitew Kifilie, A., \& Mengist, A. (2019). Bacterial infections and their antibiotic resistance pattern in Ethiopia: A systematic review. Advances in Preventive Medicine, 2019, 1-10. doi:10.1155/2019/4380309 PMID:31467724

Rogawski McQuade, E. T., Shaheen, F., Kabir, F., Rizvi, A., Platts-Mills, J. A., Aziz, F., Kalam, A., Qureshi, S., Elwood, S., Liu, J., Lima, A. A. M., Kang, G., Bessong, P., Samie, A., Haque, R., Mduma, E. R., Kosek, M. N., Shrestha, S., Leite, J. P., \& Iqbal, N. T. et al. (2020). Epidemiology of Shigella infections and diarrhea in the first two years of life using culture-independent diagnostics in 8 low-resource settings. PLoS Neglected Tropical Diseases, 14(8), e0008536. doi:10.1371/journal.pntd.0008536 PMID:32804926

Shrivastava, S., Bera, T., Roy, A., Singh, G., Ramachandrarao, P., \& Dash, D. (2007). Characterization of enhanced antibacterial effects of novel silver nanoparticles. Nanotechnology, 18(22), 225-103. doi:10.1088/0957$4484 / 18 / 22 / 225103$

Stoehr, L. C., Gonzalez, E., Stampfl, A., Casals, E., Duschl, A., Puntes, V., \& Oostingh, G. J. (2011). Shape matters: Effects of silver nanospheres and wires on human alveolar epithelial cells. Particle and Fibre Toxicology, 8(1), 425-430. doi:10.1186/1743-8977-8-36 PMID:22208550

Swarnalatha, Y., Krishnan, D., \& Rajasekar, S. P. V. (2013). Antibacterial activity of biogenic silver nanoparticles from Sphaeranthus amaranthoides. International Journal of Pharmacy and Pharmaceutical Sciences, 5, 594-596.

Thakare, S. R., \& Ramteke, S. M. (2017). Fast and regenerative photocatalyst material for the disinfection of E. coli from water: Silver nano particle anchor on MOF-5. Catalysis Communications, 102, 21-25. doi:10.1016/j. catcom.2017.06.008

Tran, Q. H., \& Le, A. T. (2013). Silver nanoparticles: Synthesis, properties, toxicology, applications and perspectives. Advances in Natural Sciences: Nanoscience and Nanotechnology, 4(3), 033001. doi:10.1088/2043$6262 / 4 / 3 / 033001$ 
Tripathi, S., Mehrotra, G. K., \& Dutta, P. K. (2011). Chitosan-silver oxide nanocomposite film: Preparation and antimicrobial activity. Bulletin of Materials Science, 34(1), 29-35. doi:10.1007/s12034-011-0032-5

Vanaja, M., Gnanajobitha, G., Paulkumar, K., Rajeshkumar, S., Malarkodi, C., \& Annadurai, G. (2013). Phytosynthesis of silver nanoparticles by Cissus quadrangularis: Influence of physicochemical factors. Journal of Nanostructure in Chemistry, 3(1), 1-8. doi:10.1186/2193-8865-3-17

Vance, M. E., Kuiken, T., Vejerano, E. P., McGinnis, S. P., Hochella, M. F. Jr, Rejeski, D., \& Hull, M. S. (2015). Nanotechnology in the real world: Redeveloping the nanomaterial consumer products inventory. Beilstein Journal of Nanotechnology, 6, 1769-1780. doi:10.3762/bjnano.6.181 PMID:26425429

Von Goetz, N., Lorenz, C., Windler, L., Nowack, B., Heuberger, M., \& Hungerbuhler, K. (2013). Migration of $\mathrm{Ag}$-and TiO2-(Nano) particles from textiles into artificial sweat under physical stress: Experiments and exposure modeling. Environmental Science \& Technology, 47(17), 9979-9987. doi:10.1021/es304329w PMID:23786648

Von White, G., Kerscher, P., Brown, R. M., Morella, J. D., McAllister, W., Dean, D., \& Kitchens, C. L. (2012). Synthesis of robust, biocompatible silver nanoparticles using garlic extract. Journal of Nanomaterials, 2012, 2012. doi:10.1155/2012/730746 PMID:24683414

Xie, Z. X., Tzeng, W. C., \& Huang, C. L. (2016). One-pot synthesis of icosahedral silver nanoparticles by using a photoassisted tartrate reduction method under UV light with a wavelength of $310 \mathrm{~nm}$. ChemPhysChem, 17(16), 2551-2557. doi:10.1002/cphc.201600257 PMID:27129025 